\title{
Full Mouth Rehabilitation Using Mandibular Bilateral Precision Attachments And Maxillary Tooth Supported Overdenture - A Case Report
}

\author{
Kalpana $\mathrm{G}^{1}$, Taruna $\mathrm{M}^{2}$, Sudhir $\mathrm{N}^{3}$, Chittaranjan $\mathrm{B}^{4}$
}

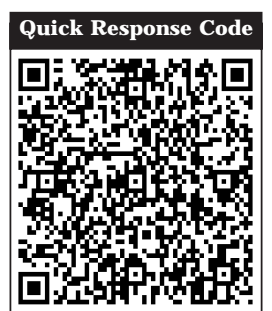

doi: $10.5866 / 2016.8 .10052$

1Post graduate student,

2-4Professor

Professor.

Department of Prosthodontics,

Kamineni Institute of Dental Sciences,

Narketpally, Nalgonda, Telangana State.

\section{Article Info:}

Received: J anuary 12, 2016

Review Completed: February 13, 2016

Accepted: March 11, 2016

Available Online: May, 2016 (www.nacd.in)

(C) NAD, 2016 - All rights reserved

\section{Email for correspondence:}

drkalpanamds9@gmail.com

\begin{abstract}
:
Full mouth rehabilitation always need a careful attention and meticulous treatment planning. Successful restoration of the dentition requires plenty of contemporary and conventional treatment techniques. Tooth supported overdenture and attachment retained partial dentures are one such kind of treatment modality in prosthodontics. Devan stated that "perpetual preservation of what remains is more important than the meticulous replacement of what is missing". So, inspite of rapid development of implant dentistry preservation of teeth that are present is more important. Precision attachments have advantage of additional retention and also help to obtain parallelism on non-parallel attachments while tooth supported over-dentures offers a lot of advantages like better retention, stability, proprioception, support to the patient. This clinical report describes the prosthodontic management of a patient with few remaining natural teeth by using tooth supported maxillary over-denture and bilateral precision attachment retained mandibular partial denture.
\end{abstract}

Key words: Tooth supported overdenture, Precision attachment, Full mouth rehabilitation.

\section{INTRODUCTION}

Preventive prosthodontics mainly emphasizes the importance of procedures that can delay or eliminate future problems by preserving the remaining oral structures. Now-a-days due to increased concern towards preventive measures, overdentures have become a reliable alternative in the construction of prostheses. Preservation of teeth, roots of one or more teeth for over-denture, offers the patient a lot of advantages like better retention, stability, proprioception, support, maintenance of alveolar bone and psychological aspect of retaining teeth. Rehabilitation of partially edentulous situations can be challenging when it comes to distal extension situations where a fixed prostheses cannot be fabricated. In patients with natural anterior teeth, bilateral posterior edentulism and with high esthetic demands, precision attachments would be the best treatment option. This clinical report 
describes the prosthodontic management of a patient with few remaining natural teeth by using tooth supported maxillary over-denture and bilateral precision attachment retained mandibular partial denture.

\section{CASE REPORT}

A 35-year old male reported to Department of Prosthodontics, Kamineni Institute of Dental Sciences with a chief complaint of missing teeth and inability to eat food. Extraoral examination showed square tapering face form and straight profile and there were no pathologic findings seen.

Intraoral examination showed teeth missing in relation to $11,12,14,16,21,22,25,26,27,34,44$ and 47; abrasion with 13, 23; grade I mobility irt 23; grade II mobility irt 24; grade III mobility irt 15, 36, 46, 47 (Figure 1 and 2). Pre-operative OPG confirmed the same (Figure 3 ).

Diagnostic casts were prepared using irreversible hydrocolloid impressions. Casts were mounted on articulator using centric relation record for diagnostic purpose. Treatment options were discussed with the patient, including extraction of 15, 24, 28, 36, 46 and 47; endodontic therapy of 13, 17, 23; and fixed restoration in mandibular anterior with distal extension bilateral precision attachment partial denture, an over-denture with or without attachments in maxilla.

\section{TREATMENT PLAN:}

1. Preprosthetic phase: Extraction of 15, 24, 28, 36, 46 and 47; Oral prophylaxis and endodontic treatment of 13, 17, 23.

2. Prosthetic phase: Abutment teeth 13,17 and 23 were reduced to $2 \mathrm{~mm}$ above the gingival level and were given dome shape with chamfer finish margin (Figure 4). A putty and light bodied addition silicon impression was made and cast was poured using die stone (Figure 5). Wax pattern of the prepared abutments were made and casting was done with $\mathrm{Ni}-\mathrm{Cr}$ alloy, trimmed, sandblasted, finished and polished. Metal coping was cemented in patient's mouth and alginate impression was made again so that custom tray could be fabricated (Figure 6). Full wax spacer was adapted on the maxillary cast and custom tray was fabricated. Border molding was done and final impression was made. Master cast was poured using dental stone. Record base was fabricated on this master cast. Tooth preparation was done irt to mandibular anterior teeth $(31,32,33,35,41,42,43,45)$ to receive FPD (Figure 7). Mesial rest seat preparation was done on 38 and 48 for providing additional support. Impression was made and poured in die stone. Following which crowns have been waxed to full contour and milled in wax for maximum guiding plane surface. The patrices were added to the axial surfaces of the abutment teeth in relation to 35 and 45 using a dental surveyor. F ollowing which casting, finishing, and veneering of the fixed component was done. The fixed component including veneered metal-ceramic crowns \& the patrices were tried in the patient mouth and a pick-up impression was made. Master cast was poured using dental stone. The master cast was duplicated with agar and a refractory cast was poured.

The wax up of framework of the removable partial denture was done, matrices of the attachments were attached to the wax pattern. Following which investing and casting of the wax pattern was done. The framework was evaluated in the patient mouth. J aw relation was done using maxillary and mandibular occlusal rims. Try-in was done and acrylization was performed (Figure 8). After cementation of FPD in relation to mandibular anterior teeth maxillary overdenture and mandibular precision attached partial denture insertion was done (Figure 9 and 10). Postoperative instructions on how to insert the prosthesis and on adequate oral hygiene maintenance were provided. Patient was scheduled on periodic recall.

\section{DISCUSSION}

Total or partial edentulism not only leads to impairment of oral function but also influences facial appearance and psychological conditions. ${ }^{1}$ Overdentures have become a common treatment alternative for partially edentulous individuals with few remaining teeth. Preservation of remaining teeth preserves the residual alveolar bone around the roots. Thus an overdenture serves several purposes like preservation of natural teeth, preservation of alveolar bone, increased masticatory efficiency. Preservation of proprioception, increases support and retention. ${ }^{2}$

In the present case report, according to the periodontal condition, distribution and the number of remaining teeth and patient's financial condition, a tooth supported over-denture would be the most appropriate treatment option for maxillary partial edentulism. Due to continued proprioceptive 


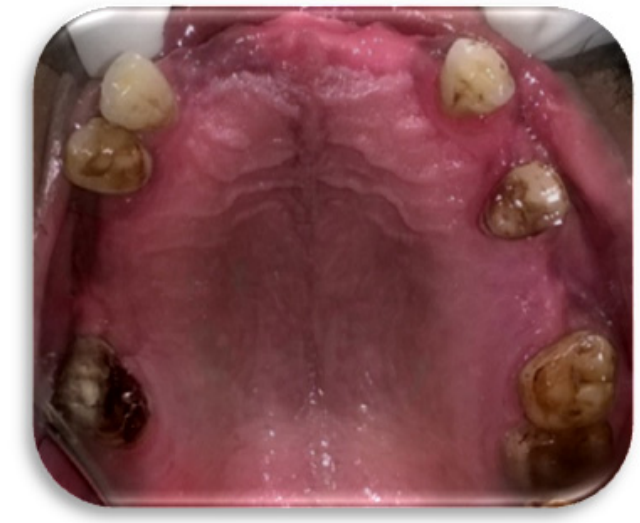

Figure 1: Maxillary preoperative intraoral view

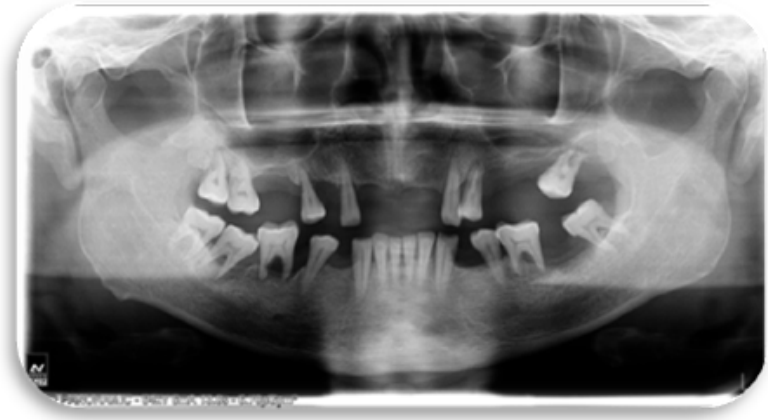

Figure 3: Preoperative radiograph

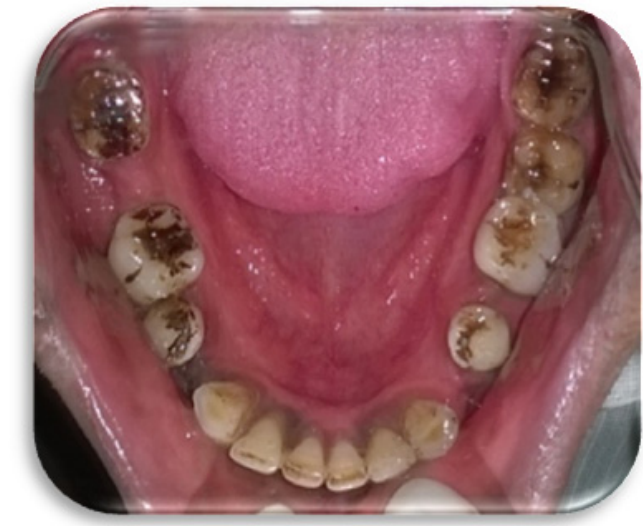

Figure 2: Mandibular preoperative intraoral view

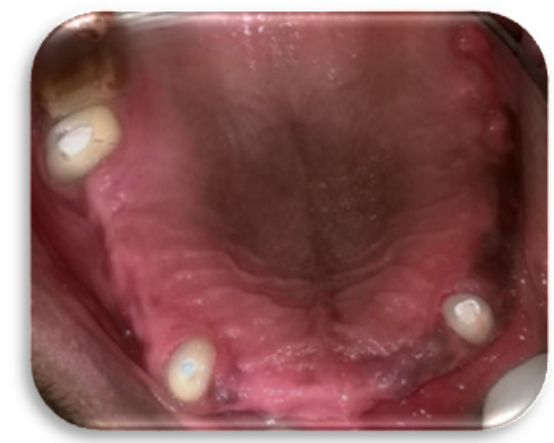

Figure 4: Maxillary Over denture abutment preparation

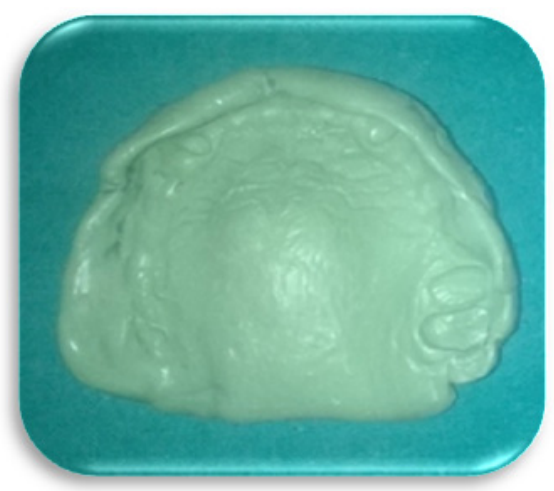

Figure 5: Maxillary final impression

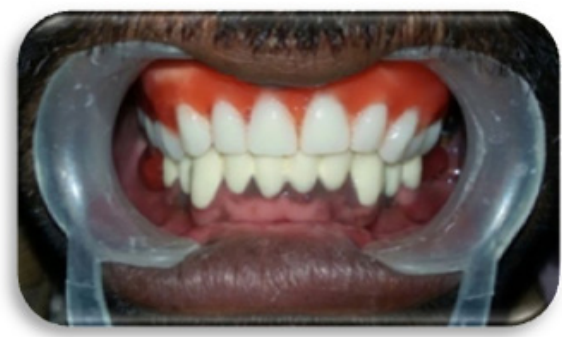

Figure 8: Try in

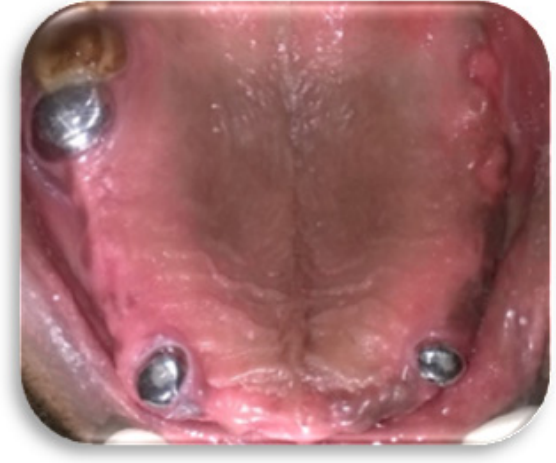

Figure 6: Maxillary arch showing metal coping cemented

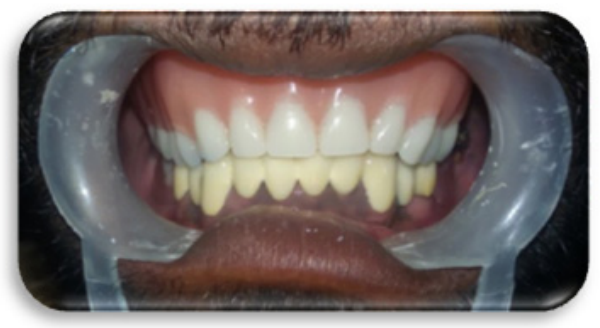

Figure 9: Insertion

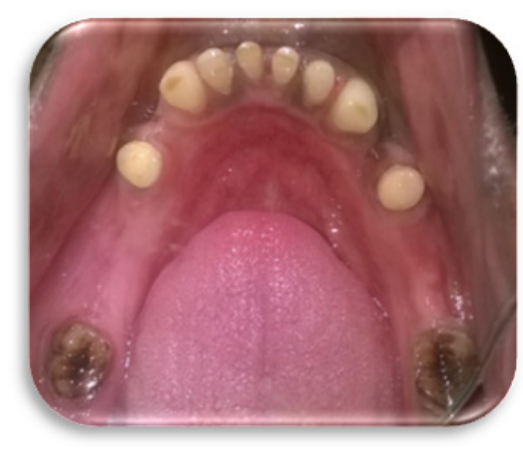

Figure 7: Mandibular tooth preparation for fpd irt 31,32,33,35,41,42,43,45

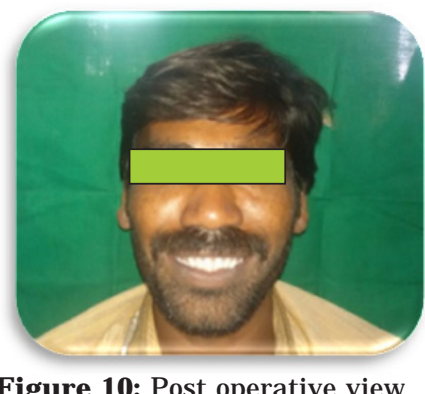

Figure 10: Post operative view 
sensation, tooth supported over-denture also prevents residual alveolar bone resorption.

Precision attachment has exceptional feature of being a removable prosthesis with improved aesthetics, less post-operative adjustments and better patient comfort. They are mostly indicated in long edentulous spans, distal extension bases and non parallel abutments.

Understanding the difference in nature and behaviour of the tissues supporting RPD is critical for long term success of the prosthesis. These differences multiplied by the function create major stresses on the tooth-tissue prosthesis. The stresscontrol on abutment is an essential factor for the success of distal extension cast partial denture which is achieved through dual impression technique, broad coverage and stable denture base, rigid design, physiologic shimming, splinting of abutments, proper selection of attachment and clasp design. ${ }^{3}$

Retainer selection for removable dental prosthesis mainly depends on the remaining tooth structure, the intra- and inter-maxillary relationships, aesthetics, and financial aspects. ${ }^{4}$

In the present case, keeping in mind the esthetic demand, periodontal condition of the remaining teeth and the financial status of the patient a removable-fixed partial denture(precision attachment) was planned. Multiple abutments anterior to edentulous span were splinted to aid in better distribution of stresses. In this patient after vertical dimension is established, anterior guidance is determined by proper overbite and overjet relationship and accordingly the occlusion of posterior teeth is established. Thus a bilateral balanced scheme of occlusion is established for the patient. I $n$ a bilateral balanced occlusion maximum numbers of teeth are in contact in maximum intercuspation and in all excursive positions. Thus it helps in maintaining denture stability; and the contacts on the non-working side prevent the denture form being dislodged from oblique forces. ${ }^{5}$

After prosthetic rehabilitation, both facial appearance and occlusion were improved. By theend of treatment plan the patient reported great satisfaction and reported better self confidence.

\section{CONCLUSION}

Tooth supported over-denture and removable partial dentures fabricated with precision attachments are the viable options for patients where retention is prime concern and economic condition does not permit the use of dental implants. Proper diagnosis and periodic recall preventative therapy will result in successful treatment and preservation of the patient's existing dentition.

\section{REFERENCES}

1. Dolu Omur Dede, Cenk Durmu Glar M, Onur Fahjn, Aygegul Korollu, Ozer Egjsal. Telescopic Overdenture and Implant Supported Fixed Partial Denture: A Pragmatic Treatment Approach. Case Reports Dent 2015.

2. Shikha J indal, Roma Goswami, Singh SP. Metal reinforced mandibular overdenture with bar Attachment. e-journal of dentistry 2013; 3(3).

3. Sumit Makkar, Anuj Chhabra, Amit Khare.Attachment Retained Removable Partial Denture: A CaseReport. IJ CDS 2011; 2(2).

4. Nitin Bhaskar Shetty, Sanyuktha Shetty, Nagaraj E, Omkar Shetty, Raina D'souza M. Precision Attachments for Aesthetics and Function: A Case Report. J CDR 2014; 8(1):268-70.

5. Sujana J asthi et al. Multidisciplinary Approach for Rehabilitation of Young Adult with Amelogenisis I mperfecta Indian J Dent Adv 2014; 6(3):1633-6.

\section{Gain quick access to our journal online View our journal at www.nacd.in}

